\title{
Adjunctive Varenicline Treatment with Antipsychotic Medications for Cognitive Impairments in People with Schizophrenia: A Randomized Double-Blind Placebo-Controlled Trial
}

\author{
Joo-Cheol Shim*, 1,2, Do-Un Jung ${ }^{1}$, Sung-Soo Jung ${ }^{3}$, Young-Soo Seo ${ }^{3}$, Deuk-Man Cho ${ }^{4}$, Ji-Heon Lee ${ }^{5}$, \\ Sae-Woom Lee ${ }^{5}$, Bo-Geum Kong', Je-Wook Kang', Min-Kyung Oh ${ }^{2,6}$, Sang-Duk Kim ${ }^{7}$, \\ Robert P McMahon ${ }^{8}$ and Deanna L Kelly \\ 'Department of Psychiatry, College of Medicine, Inje University, Busan, Republic of Korea; ${ }^{2}$ Clinical Trial Center, Busan Paik Hospital, \\ Inje University, Busan, Republic of Korea; ${ }^{3}$ Sharing and Happiness Hospital, Busan, Republic of Korea; ${ }^{4}$ Hyungju Hospital, Busan, Republic of \\ Korea; ${ }^{5}$ Jamyeong Hospital, Busan, Republic of Korea; ${ }^{6}$ Department of Pharmacology, College of Medicine, Inje University, Korea; ${ }^{7}$ Pusan Veteran \\ Hospital, Busan, Republic of Korea; ${ }^{8}$ Maryland Psychiatric Research Center, University of Maryland School of Medicine, Baltimore, MD, USA
}

\begin{abstract}
The aim of this study is to examine the effects of treatment with varenicline, a partial agonist at the $\alpha 4 \beta 2$ and full agonist at the $\alpha 7$ nicotine acetylcholine receptor, on cognitive impairments in people with schizophrenia. In all, 120 clinically stable people with schizophrenia participated in randomized, double-blind, placebo-controlled 8-week trial. Antipsychotic and concomitant medication doses remained fixed throughout the study. Varenicline was titrated up to I mg twice daily for weeks 2-8. Neuropsychological, clinical, and safety assessments were administered at baseline and weeks I, 2, 4, and 8 . In the primary analyses of neurocognitive differences at week 8, no varenicline-placebo differences were significant. In secondary longitudinal analyses, varenicline improved compared with placebo on the Digital Symbol Substitution Test $(p=0.013)$ and the Wisconsin Card Sorting Test non-perseverative errors $(p=0.043)$. Some treatment effects were different between smokers and non-smokers. In smokers, Continuous Performance Test hit reaction time $(p=0.008)$ and Stroop Interference $(p=0.004)$ were reduced for varenicline compared with placebo, while there were no treatment differences in non-smokers. No significant treatment main effects or interactions were noted for total scores on the Positive and Negative Syndrome Scale or the Scale for the Assessment for Negative Symptoms. Our findings suggest beneficial effects of adjunctive varenicline treatment with antipsychotics for some cognitive impairments in people with schizophrenia. In some cases, effects of treatment varied between smokers and non-smokers. Further study is required to assess the functional significance of these changes. Neuropsychopharmacology (2012) 37, 660-668; doi:I0.1038/npp.20 I 1.238; published online 2 November 20 I I
\end{abstract}

Keywords: schizophrenia; cognition; varenicline; antipsychotics; smoking

\section{INTRODUCTION}

Cognitive impairments have been considered a core symptom domain of schizophrenia (Green, 2006). Considerable evidence supports the hypothesis that nicotine, through the nicotinic acetylcholine receptor (nAChR) system, may be effective in improving cognitive deficits in people with schizophrenia. Nicotine administration improves attention and working memory deficits (Sacco et al,

*Correspondence: Dr J-C Shim, Department of Psychiatry and Clinical Pharmacology, Busan Paik Hospital, Inje University, 633-165 Gaegumdong, Busanjin-gu, Busan 614-735, Republic of Korea, Tel: + 8251890 6433, Fax: + 8251894 2532, E-mail: jooshim@inje.ac.kr Received I4 January 2011; revised 23 August 2011; accepted 28 August 2011
2005; Barr et al, 2008; Jubelt et al, 2008), while abstinence from cigarette smoking may worsen visuospatial working memory in people with schizophrenia (George et al, 2002). Adjunctive nicotine administration significantly attenuated memory impairments caused by antipsychotic medications on a study in rats (Addy and Levin, 2002). The two main nAChR subtypes in the brain $(\alpha 4 \beta 2$ and $\alpha 7)$ have both been implicated in cognitive processes (Bencherif and Schmitt, 2002). $\alpha 4 \beta 2$ receptors have a very high affinity for nicotine and desensitize at low concentrations of nicotine, corresponding to blood concentrations experienced by smokers. In contrast, $\alpha 7$ receptors have a low affinity for nicotine but do not desensitize at low nicotine concentrations (Poorthuis et al, 2009). In animal studies, local acute and chronic hippocampal infusion of $\alpha 4 \beta 2$ antagonists cause significant spatial working memory impairment (Arthur and Levin, 
2002), while $\alpha 4 \beta 2$ receptor agonists significantly improve working memory and attention function (Levin et al, 2002). Abnormal expression of $\alpha 4 \beta 2$ and $\alpha 7$ nicotinic receptors is found in post-mortem hippocampus and prefrontal cortex of schizophrenia patients (Breese et al, 2000; Marutle et al, 2001).

Varenicline binds to $\alpha 4 \beta 2 \mathrm{nAChRs}$ and with low affinity to $\alpha 7 \mathrm{nAChRs}$ (Mihalak et al, 2006). Varenicline is a partial agonist with $45 \%$ of nicotine's maximal efficacy at $\alpha 4 \beta 2$ nAChRs (Rollema et al, 2007) and stimulates dopamine release from rat nucleus accumbens (Coe et al, 2005), which is mediated via interactions with $\alpha 4 \beta 2 \mathrm{nAChRs}$ in the ventral tegmental area, similar to nicotine-evoked DA release (Maskos et al, 2005).

To date, no well-controlled clinical trials have been published which examine the efficacy of varenicline in treating cognitive impairments in people with schizophrenia. The objective of this study was to examine the effects of varenicline treatment on cognitive impairments in people with schizophrenia.

\section{PARTICIPANTS}

This study was a randomized, double-blind, placebocontrolled 8-week trial with 120 outpatients with chronic schizophrenia (60 smokers and 60 non-smokers) participating. Inclusion criteria included a DSM-IV diagnosis of schizophrenia, 18-60 years of age, and considered clinically stable with less than moderate severity (Positive and Negative Syndrome Scale (PANSS) total score $\leqslant 75$; Leucht et al, 2005) for at least 3 months before participating in this trial. Smokers were included if they smoked $>10$ cigarettes daily for $\geqslant 1$ year and had fewer than 3 months of smoking abstinence within the last year. Non-smokers included those who did not smoke a cigarette in the last year. Exclusion criteria included any serious or unstable medical disorder within the preceding 6-month period, other DSM-IV axis I diagnoses, substance abuse or dependence (other than nicotine) in 12 months before participating in this study, pregnant or breast feeding, considered at high risk of suicide. Subjects were excluded if they currently used tobacco products other than cigarettes or any form of nicotine replacement therapy. Subjects with a history of taking clozapine were excluded, because they were less amendable to cognitive improvement therapy. All subjects gave written informed consent. Subject recruitment was conducted competitively at five sites in Korea and was approved by the Institutional Review Board at Inje University. Recruitment from each site ranged from 20 to 25 subjects and continued to a pre-specified total of 120 participants.

\section{MEDICATIONS}

Participants took antipsychotic medication at the time of study inclusion. Antipsychotic dosing and concomitant medications remained fixed throughout the study. Daily doses of antipsychotic medications were converted into chlorpromazine equivalents following Woods (2003). Simple randomization was used to assign participants to varenicline or placebo within strata defined by site and smoking status, but not by antipsychotic medications. Medication allocation was concealed from patients and research staff by using identically appearing varenicline and sucrose placebo capsules. Doses of varenicline or matching placebo were titrated upward as follows: varenicline $0.5 \mathrm{mg}$ for days $1-3,0.5 \mathrm{mg}$ twice per day for days $4-7$, then $1 \mathrm{mg}$ twice daily for weeks 2-8. Lorazepam PRN (1-4 mg/day) was permitted for anxiety and insomnia, but was not administered $12 \mathrm{~h}$ before neuropsychological testing. Anticholinergic medications were also permitted; however, the doses were to remain fixed throughout the study.

\section{EFFICACY MEASURES}

\section{Neuropsychological Assessment}

The neuropsychological test battery was selected to focus on attention and was administered at baseline and weeks 1, 2, 4 , and 8. To minimize acute nicotine effects or nicotine withdrawal, on the morning of clinical ratings and neurocognitive testing all subjects who were smokers, smoked ad lib until $1 \mathrm{~h}$ before testing, when they smoked one cigarette and then abstained. Participants who were non-smokers did not smoke before the neurocognitive testing.

Continuous Performance Test. The Conners Continuous Performance Test-II (Conners, 2004) measures sustained attention, concentration, and response inhibition. Hit reaction time is defined as the mean response time (milliseconds) for all target responses. Detectability, a measure of how well the individual discriminates between targets and non-targets, was summarized by d-prime $=$ $\Phi^{-1}$ (hit rate) $-\Phi^{-1}$ (false alarm rate), where $\Phi^{-1}(x)$ is the value of a standard normal random variable corresponding to a cumulative probability equal to $x$.

Stroop Color Word Test. The Stroop Color Word Test measures participants' ability to shift their perceptual set to conform to changing conditions requiring mental control, response conflict, and selective attention with the occurrence of perceptual interference (Lezak, 1995). Participants are shown color words ('Red' or 'Green') printed in matching or incongruent colors and are asked to report the ink color. The difference in time (milliseconds) required to correctly name the ink color between trials when the ink does or does not match the color word is termed 'Stroop Interference'.

Wisconsin Card Sorting Test. The Wisconsin Card Sorting Test (Heaton et al, 1993) assesses executive functions, including conceptual flexibility in response to feedback. Using the computerized Wisconsin Card Sorting Test CV3 software program, a total of 128 cards are presented and the test requires participants to sort the cards on the basis of the color, shape, or number of figures. Common outcomes reported are categories completed, percent total errors, percent perseverative errors, and percent non-perseverative errors.

Digital Symbol Substitution Test. In the Digit Symbol Substitution Test, a subtest of the Wechsler Adult Intelligence Scale-Revised (Wechsler, 1981), a series of nine 
symbols is presented and subjects are encouraged to translate the symbols into the digits 1-9 as fast as possible within a preset 90-s limit. This test is a psychomotor performance that is relatively unaffected by intellectual prowess, memory, or learning.

Digit Span Test. The Digit Span Test, a subtest of the Wechsler Adult Intelligence Scale-Revised, measures immediate memory span to assess attention, concentration, and working memory. The subset consists of forward and backward conditions in which the examiner reads aloud series of numbers which increase in length; the participant is requested to repeat the numbers in the same or reverse order after each series is presented.

Visual Span Test. The Visual Span Test, a subset of the Memory Assessment Scale (Golden et al, 1999), assesses visual memory span. The test consists of dots on a sheet of paper and the administration procedure of Visual Span Test is similar to that of Digit Span Test, requiring two trials at each level regardless of whether the first was passed or not.

Alternate forms of the Digit Symbol Substitution test, Digital Span test, Visual Span Test, and Stroop test were used to avoid administering the same form of a test immediately after the previous administration.

\section{Smoking Assessment}

In the smoking group, numbers of cigarettes smoked per day and exhaled carbon monoxide were assessed to measure intensity of smoking at baseline and weeks 1, 2, 4, and 8, as well as other smoking-related measures not reported on in the current manuscript.

\section{Clinical Assessments}

Schizophrenia symptomatology was measured at baseline and weeks 1, 2, 4, and 8. The PANSS (Kay et al, 1987), the modified form of the Scale for the Assessment for Negative Symptoms (SANS; Andreasen, 1982), the Hamilton Depression Rating Scale (HAM-D; Hamilton, 1960), and the Clinical Global Impression severity (CGI severity) of illness assessments (Guy and Bonato, 1970) were administered.

Safety assessments performed at baseline and weeks 1, 2, 4, and 8 included the Simpson-Angus Rating Scale (Simpson and Angus, 1970), the Barnes Akathisia Rating Scale (Barnes, 2003), and a Side Effect Checklist (Kelly et al, 2009).

Neuropsychological and clinical assessments were performed by three psychiatrists at Busan Paik Hospital, Inje University. To ensure inter-rater reliability, all raters had successfully completed rater training before participation in the study, achieving an ICC $>0.75$ compared with the experienced trainer on standard videotapes on symptom rating scales.

\section{Statistical Methods}

At baseline, differences among groups were tested using Student's T-test, Wilcoxon Rank Sum test, ANOVA, and Kruskal-Wallis test for continuous measures and Pearson's $\chi^{2}$-test and Fisher's exact test for categorical measures. The pre-specified primary analysis compared treatment groups on change scores between baseline and week 8 for neurocognitive outcomes for completers, combining results from smokers and non-smokers in the absence of strong prior evidence for differences in the treatment effects by smoking status. All tests were two-tailed and significance was defined as an $\alpha<0.05$. In secondary intention to treat analyses to incorporate all follow-up data from any participant with a post-baseline neuropsychological or symptom assessment, mixed model analysis of covariance (ANCOVA) estimates were used for analyzing main effects of treatment and smoking, and their interaction, using the model: follow-up score $=$ baseline score + treatment + smoking + week + treatment $\times$ smoking + treatment $\times$ week + smoking $\times$ week + treatment $\times$ smoking $\times$ week. Adjustment for the baseline score removes the effect of baseline differences in cognitive performance between treatment groups or smokers $v s$ non-smokers from the estimated smoking or treatment effects. In this model, 'week' was treated as a categorical measure rather than continuous, because we did not have data to support the strong assumption of linearly increasing treatment effects over time implied by treating week as a continuous variable. The treatment main effect estimates the average across weeks 1 , 2,4 , and 8 of the adjusted varenicline-placebo differences at each follow-up week. The treatment $\times$ week interaction tests whether the week-by-week estimates of varenicline-placebo differences vary significantly in size among weeks. The treatment $\times$ smoking interaction estimates the average difference (across weeks) in the size of estimated varenicline-placebo differences in smokers compared with nonsmokers. Effect sizes, $d$, were calculated by dividing estimates of adjusted treatment differences by the pooled standard deviation (estimated by SAS PROC VARCOMP from the square root of the sum of within- and betweenparticipant variance components during follow-up). To evaluate a potential mediating role of changes in smoking intensity on cognitive outcomes in smokers, we separately added changes in number of cigarettes smoked daily and expired CO to the mixed model: cognitive score $=$ treatment + week + smoking intensity + treatment $\times$ week + smoking intensity $\times$ week + treatment $\times$ smoking intensity $\times$ week, where smoking intensity is the level of expired $\mathrm{CO}$ or cigarettes per day in the current week. No treatment $\times$ week, smoking $\times$ week or treatment $\times$ smoking $\times$ week interactions were significant (data not shown), and results of these tests are omitted for brevity. Secondary analyses on varenicline effects on smoking behavior are being reported elsewhere and will be clearly stated that they come from secondary analysis of a trial examining cognition which was not designed to promote smoking cessation.

\section{Demographic and Clinical Characteristics of Participants}

Ninety-one patients completed the study (45 varenicline and 46 placebo). About 25\% (29/117) subjects discontinued from the study (15/60 varenicline and $14 / 60$ placebo). Most dropouts occurred within the first 4 weeks (eight patients with adverse events withdrawn within 2 weeks; four with aggravated psychotic symptoms withdrawn between weeks 2 and 4). Causes of dropout are listed in Figure 1. Three 


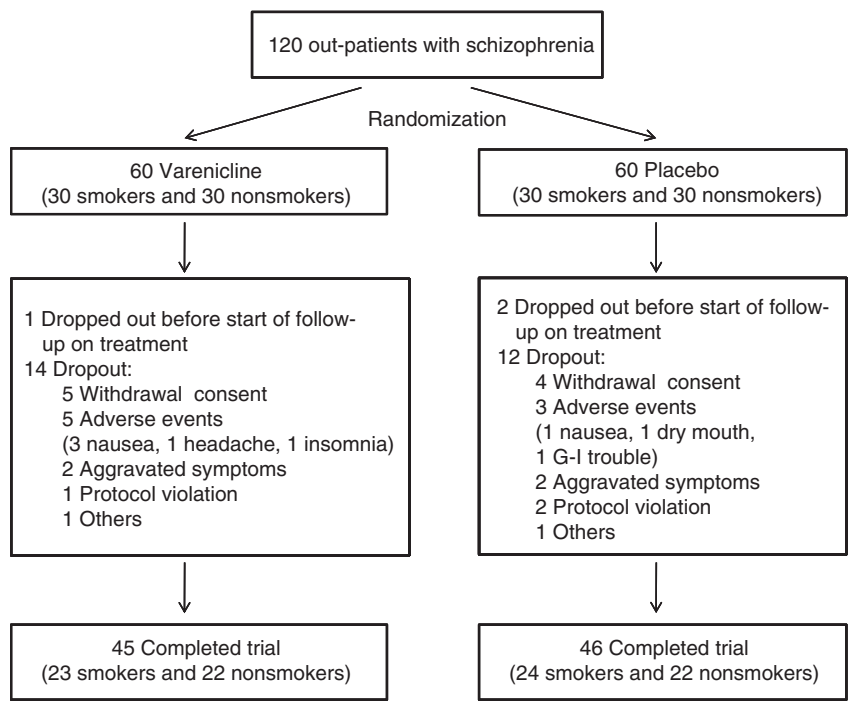

Figure I Diagram of participation in the study.

subjects were withdrawn from the study just after randomization and before the start of treatment, and were excluded from the analyses. Demographic and clinical characteristics are presented in Table 1. No significant differences between groups were found in age, sex, body mass index, percent of smokers, or amount of cigarette smoking. Baseline psychiatric symptom scores did not differ significantly between groups. No significant baseline differences in any measures were found between completers and non-completers (data not shown).

\section{Neuropsychological Data}

Cognitive function at baseline. There were no significant baseline differences between the varenicline and placebo groups in mean scores on any neuropsychological tests (Table 1). One-way analyses of variance of baseline comparability in cognitive function among the four groups: varenicline (smokers and non-smokers) vs placebo (smokers and non-smokers), suggested that at baseline, no significant main effect of smoking on cognition was observed. Supplementary Table 1 shows demographic information by group and smoking status.

Effect of treatment and time on cognitive function. In the primary analysis comparing mean change scores for neuropsychological tests between baseline and week 8 , no significant treatment differences were found on any test (Table 2). A mixed model for repeated measures was used to estimate the magnitude of changes from baseline (possible practice effects) at weeks $1,2,4$, and 8 within the placebo group (Table 2). Tests showing potential practice effects included: CPT detectability, Digit Symbol Substitution Test, Digit Span Forward, Stroop Interference, and Wisconsin Card Sort Test categories. In the secondary analysis using mixed model ANCOVA generally similar results were seen for time main effects, averaged across treatment groups, although additional time effects were seen for Wisconsin Card Sorting Test category completed $(\mathrm{F}=2.91, \mathrm{df}=3373$, $p=0.034$ ); Wisconsin Card Sorting Test total error
$(\mathrm{F}=3.67, \mathrm{df}=3257, p=0.012)$; and Wisconsin Card Sorting Test perseverative error $(\mathrm{F}=2.81, \mathrm{df}=3185, p=0.041)$.

On two tests (Table 3), the average of the week-by-week adjusted varenicline-placebo differences (treatment main effects) was statistically significant: Digital Symbol Substitution Test (difference \pm standard error $(\mathrm{SE})=1.86 \pm$ $0.75, d=0.13, \mathrm{~F}=6.15, \mathrm{df}=1375, p=0.013)$ and Wisconsin Card Sorting Test non-perseverative error $(-2.37 \pm 1.17$, $d=0.21, \mathrm{~F}=4.12, \mathrm{df}=1311, p=0.043)$; both differences reflected improvement for varenicline relative to placebo. In addition, a marginal trend was present for reduced Continuous Performance Test hit reaction time with varenicline compared with placebo $(-1.76 \pm 0.97, d=0.12$, $\mathrm{F}=3.26, \quad \mathrm{df}=1276, \quad p=0.07) . \quad$ No significant treatment $\times$ time interactions were present in any test.

Treatment effects on cognitive function by smoking status. Estimated varenicline-placebo differences from mixed model ANCOVA, averaged over weeks 1, 2, 4, and 8, are displayed by smoking status in Table 3. Estimated varenicline-placebo differences by week and smoking status are shown in Supplementary Table 2. The mixed model ANCOVA found significant differences (Table 4) between smokers and non-smokers in the size of the average varenicline-placebo differences for several tests (treatment $\times$ smoking interactions). Continuous Performance Test hit reaction time was significantly reduced for varenicline $v s$ placebo in smokers (difference \pm $\mathrm{SE}=-3.7 \pm 1.4, d=0.26, t=2.64, \mathrm{df}=1, p=0.008)$, but not in non-smokers (treatment $\times$ smoking interaction: $\mathrm{F}=4.13, \mathrm{df}=1376, p=0.042)$. Stroop Interference was significantly reduced for varenicline relative to placebo in non-smokers (difference $\pm \mathrm{SE}=-4.40 \pm 1.51, \quad d=0.38$, $t=2.91, \quad \mathrm{df}=1, \quad 375, \quad p=0.004)$, but not in smokers (treatment $\times$ smoking interaction: $\mathrm{F}=4.66, \mathrm{df}=1375$, $p=0.009$ ). For the remaining neuropsychological tests, varenicline-placebo differences were not significantly different in smokers $v s$ non-smokers (Table 2). Significant average smoker-non-smoker differences (smoking main effects) were found for several tests, including Continuous Performance Test detectability (mean $\pm \mathrm{SE}=-0.14 \pm 0.04$, $d=0.12, \mathrm{~F}=13.09, \mathrm{df}=1,376, p=0.003)$; Digital Symbol Substitution Test $\quad($ mean $\pm \mathrm{SE}=-1.64 \pm 0.74, \quad d=0.14$ $\mathrm{F}=4.96, \quad \mathrm{df}=1375, \quad p=0.026) ;$ and Visual span total (mean $\pm \mathrm{SE}=0.52 \pm 0.15, \mathrm{~F}=11.92, d=0.05, \mathrm{df}=1, \quad 374$, $p=0.001$ ). See also Supplementary Table 3 and Supplementary Figure 1 for additional data.

No smokers in either treatment group quit smoking entirely. Some changes in smoking intensity measures (cigarettes per day, expired CO) were seen in smokers, especially in the varenicline group (data to be reported separately). To examine whether these smoking changes mediated (accounted for) observed differences in cognitive change in the varenicline group, we added the change in expired CO or cigarettes per day at weeks $1,2,4$, and 8 to the mixed model analyzing treatment effects on cognition at those weeks. The results of these mediation models indicated that (1) changes in cigarettes per day or expired CO did not show a statistically significant effect on cognitive measures and (2) adding expired $\mathrm{CO}$ or cigarettes per day to the mixed models did not importantly alter the estimated magnitude of treatment effects (data not shown). 
Table I Demographic and Baseline Clinical Characteristics of Subjects

Demographic and clinical characteristic
Sex
Male

Varenicline

$(n=59)$

Placebo

$(n=58)$
38

21
45

13

Age (years)
Body mass index $\left(\mathrm{kg} / \mathrm{m}^{2}\right)$
Education (years)
Age, onset of illness (years)
Duration of illness (years)
Korean version of Wechsler Adult
Intelligence Scale (Full scale IQ)
Positive and Negative Syndrome
Scale Total
Scale for the Assessment of
Negative Symptoms Total
Clinical Global Impression Severity
Hamilton Depression Rating Scale
Total
Simpson-Angus Rating Scale
Barnes Akathisia Rating Scale

$\begin{array}{ccccl}\text { Mean } & \text { SD } & \text { Mean } & \text { SD } & \\ 39.9 & 8.6 & 39.9 & 9.9 & \\ 21.7 & 3.5 & 22.3 & 3.5 & \text { Dose }(\mathrm{mg} / \text { day }) \\ 12.6 & 2.6 & 12.1 & 3.1 & \\ 26.1 & 6.7 & 25.9 & 6.6 & \\ 13.5 & 7.8 & 14.2 & 9.9 & \text { Antidepressants } \\ 92.0 & 15.0 & 86.4 & 12.9 & \text { Antianxiety agents } \\ & & & & \text { Mood stabilizers } \\ 61.4 & 16.0 & 64.1 & 16.4 & \text { Others }\end{array}$

Table I Continued the analysis. placebo groups.

\begin{tabular}{|c|c|c|c|c|}
\hline \multirow[b]{2}{*}{$\begin{array}{l}\text { Combined second- and first- } \\
\text { generation antipsychotics }\end{array}$} & \multicolumn{2}{|c|}{$\begin{array}{c}\text { Varenicline } \\
(n=59)\end{array}$} & \multicolumn{2}{|c|}{$\begin{array}{l}\text { Placebo } \\
(n=58)\end{array}$} \\
\hline & 8 & 13.6 & 9 & 15.5 \\
\hline \multicolumn{5}{|l|}{ Combined medications } \\
\hline & N & $\%$ & N & $\%$ \\
\hline \multirow[t]{2}{*}{ Anticholinergics, Benztropine } & 40 & 67.8 & 48 & 82.8 \\
\hline & Mean & SD & Mean & $\mathrm{SD}$ \\
\hline \multirow[t]{2}{*}{ Dose (mg/day) } & 0.74 & 0.31 & 0.68 & 0.35 \\
\hline & N & $\%$ & N & $\%$ \\
\hline Antidepressants & 5 & 8.5 & 4 & 6.9 \\
\hline Antianxiety agents & 24 & 40.7 & 28 & 48.3 \\
\hline Mood stabilizers & ।1 & 18.6 & 11 & 19.0 \\
\hline Others & 12 & 20.3 & 14 & 24.1 \\
\hline
\end{tabular}

Three subjects who discontinued right after randomization are excluded from

No significant difference was found in all variables between varenicline and

\section{Clinical and Safety Data}

In a mixed model ANCOVA, no significant main effects of treatment or time by treatment group interactions were noted in the PANSS and SANS total scores or CGI severity. Two patients each in the varenicline and placebo groups showed aggravated psychotic symptoms and were withdrawn from the study. No subjects in either group had increases in depressive symptoms measured by HAM-D. Overall, no significant changes were noted in the SimpsonAngus Scale and Barnes Akathisia Rating Scale scores over time in either drug group. For cumulative percentages of patients showing new or worsened side effects over the entire study, nausea $\left(30.5 \%\right.$ vs $10.3 \% ; \chi^{2}=7.29, \mathrm{df}=1$, $p=0.007)$ and headache $(10.2 \%$ vs $0.0 \%$; Fisher's exact test, $p=0.027$ ) were significantly higher with varenicline compared with placebo.

This double-blind, placebo-controlled study evaluated the effect of varenicline on cognitive dysfunction in people with schizophrenia. Overall, our findings suggest some beneficial effects of adjunctive varenicline for cognitive impairments in people with schizophrenia. Statistically significant cognitive improvements were seen on the Digital Symbol Substitution Test $(d=0.14)$ and the Wisconsin Card Sorting Test non-perseverative error $(d=0.13)$. In some cases, baseline smoking status altered treatment effects: varenicline improved compared with placebo on Continuous Performance Test hit reaction time among smokers $(d=0.26)$ and on Stroop Interference among non-smokers $(d=0.38)$. In addition, on Digit Span Backward, estimated varenicline-placebo differences were in opposite directions $(d=0.15)$ in smokers (trend toward improvement) compared with non-smokers $(d=0.12)$ trend toward worsening; $p=0.03$ for treatment $\times$ smoking interaction, although not 
Table 2 Primary Outcome Analysis: Changes in Neurocognitive Outcomes from Baseline to Week 8 by Treatment Group

\begin{tabular}{|c|c|c|c|c|c|c|c|c|c|}
\hline \multirow[t]{2}{*}{ Neurocognitive outcome } & \multicolumn{3}{|c|}{ Varenicline } & \multicolumn{3}{|c|}{ Placebo } & \multicolumn{3}{|c|}{$\begin{array}{l}T \text {-test for treatment difference } \\
\text { in change scores }\end{array}$} \\
\hline & $\mathbf{N}$ & Mean & SD & $\mathbf{N}$ & Mean & SD & $T$ & df & $P$-value \\
\hline Continuous Performance Test hit reaction time & 46 & -1.34 & 10.61 & 45 & 0.16 & 10.60 & -0.68 & 89 & 0.5000 \\
\hline Continuous Performance Test detectability & 46 & 0.21 & 0.45 & 45 & 0.20 & 0.43 & 0.08 & 89 & 0.9397 \\
\hline Digital Symbol Substitution Test & 46 & 7.24 & 9.28 & 45 & 5.78 & 7.49 & 0.83 & 89 & 0.4113 \\
\hline Digit Span Backward & 45 & 0.13 & 1.62 & 45 & 0.44 & 1.74 & -0.88 & 88 & 0.3821 \\
\hline Visual Span & 46 & 0.07 & 1.62 & 45 & 0.42 & 1.62 & -1.05 & 89 & 0.2963 \\
\hline Stroop Interference T score & 46 & -4.48 & 8.39 & 45 & -3.36 & 11.09 & -0.55 & 89 & 0.5868 \\
\hline Wisconsin Card Sorting Test categories & 46 & 0.89 & 2.30 & 44 & 0.70 & 1.68 & 0.44 & 82.32 & 0.6603 \\
\hline Wisconsin Card Sorting Test non-perseverative error & 39 & 5.49 & 13.41 & 35 & 4.46 & 10.46 & 0.37 & 72 & 0.7157 \\
\hline
\end{tabular}

Data are presented as mean and SD for change scores (week 8 minus baseline) by group for each of the cognitive outcomes, together with test statistics from $t$-test for difference in change scores on each test.

Table 3 Learning Effects on Neuropsychological Outcome Measures Changes from Baseline by Follow-up Week, Placebo Group

\begin{tabular}{|c|c|c|c|c|c|c|c|c|c|c|c|c|}
\hline \multirow[t]{3}{*}{ Neuropsychological measurement } & \multicolumn{8}{|c|}{ Estimated changes from baseline } & \multicolumn{4}{|c|}{$\begin{array}{l}\text { Overall test for any } \\
\text { change among weeks }\end{array}$} \\
\hline & \multicolumn{2}{|c|}{ Week I } & \multicolumn{2}{|c|}{ Week 2} & \multicolumn{2}{|c|}{ Week 4} & \multicolumn{2}{|c|}{ Week 8} & \multirow{2}{*}{$\mathbf{F}$} & \multirow{2}{*}{\multicolumn{2}{|c|}{ df }} & \multirow{2}{*}{$P$-value } \\
\hline & Mean & SE & Mean & SE & Mean & SE & Mean & SE & & & & \\
\hline Continuous Performance Test hit reaction time & 0.17 & 1.13 & -1.30 & 1.20 & -0.78 & 1.16 & 0.03 & 1.51 & 0.48 & 4 & 43.9 & 0.7483 \\
\hline Digital Symbol Substitution Test & $3.16 *$ & 0.68 & $5.29 *$ & 0.79 & $5.61 *$ & 0.88 & $6.28 *$ & 1.09 & 11.69 & 4 & 44.3 & $<.0001$ \\
\hline Digit Span Forward & $0.48 *$ & 0.23 & $0.43 *$ & 0.21 & $0.82 *$ & 0.23 & $0.98 *$ & 0.22 & 5.47 & 4 & 46.4 & 0.0011 \\
\hline Digit Span Backward & 0.04 & 0.21 & $0.49 *$ & 0.20 & 0.27 & 0.20 & 0.48 & 0.26 & 1.99 & 4 & 43 & 0.1130 \\
\hline Visual Span & 0.45 & 0.23 & 0.45 & 0.24 & 0.39 & 0.20 & $0.48 *$ & 0.23 & 1.79 & 4 & 43.4 & 0.1486 \\
\hline Stroop Interference & -1.07 & 2.13 & -1.98 & 1.95 & $-3.67 *$ & 1.69 & $-4.06 *$ & 1.46 & 6.41 & 4 & 46.1 & 0.0003 \\
\hline
\end{tabular}

Post hoc $t$-tests from mixed model were performed to compare individual follow-up weeks with baseline. The overall F-test for any change among weeks and post $t$-tests come from the mixed model ANOVA.

* $p<0.05$.

significantly different from zero in either smoking status group. In no case did patients assigned to varenicline perform significantly worse than those on placebo. These nominally significant findings occurred on two of nine tests for treatment main effects and three of nine tests for smoking by treatment interaction, and would not be considered significant after adjustment for multiple comparisons. Accordingly, we cannot rule out that these interesting results are due to chance.

It is a common phenomenon that progressive improvement is seen following repeated cognitive function battery administration (Kantrowitz et al, 2009). In this study, significant time main effects detected for a number of variables suggested that some change due to learning effects in both treatment groups.

In previous studies in people with schizophrenia, smoking improved Continuous Performance Test hit reaction time (Levin et al, 1996), Card Stroop Test (Barr et al, 2008),
Wisconsin Card Sorting Test (Rabin et al, 2009), and Visuospatial Working Memory (Sacco et al, 2005), while abstinence from cigarette smoking may worsen visuospatial working memory in people with schizophrenia (George et al, 2002). In mixed model ANCOVAs in our study, baseline smoking was related to average improvements in both groups on the Continuous Performance Test, Digital Symbol Substitution Test, and Visual Span test. However, our secondary analyses of effects of expired $\mathrm{CO}$ and cigarettes on cognition in the smoking groups demonstrated little effect of changes in these quantitative markers of nicotine exposure on the neurocognitive functioning, nor any evidence that changes in smoking intensity mediated varenicline effects on cognition. Failure to detect cognitive effects of the significant reductions in daily smoking intensity some participants achieved during this trial might be accounted for in part by our requirement that smokers consume one cigarette an hour before testing, and thereafter 
Table 4 Mixed Model Estimates of Treatment Differences by Cognitive Outcome and Smoking Status

\begin{tabular}{|c|c|c|c|c|c|c|c|c|c|c|c|c|c|c|c|c|}
\hline \multirow[t]{2}{*}{ Test } & \multicolumn{6}{|c|}{ Smokers } & \multicolumn{6}{|c|}{ Non-Smokers } & \multicolumn{4}{|c|}{$\begin{array}{c}\text { Test for treatment } \times \text { smoking } \\
\text { interaction }\end{array}$} \\
\hline & $\begin{array}{l}\text { Varenicline- } \\
\text { Placebo }\end{array}$ & SE & $\begin{array}{l}\text { Effect } \\
\text { size }\end{array}$ & $t$ & df & $P$ & $\begin{array}{l}\text { Varenicline- } \\
\text { Placebo }\end{array}$ & SE & $\begin{array}{l}\text { Effect } \\
\text { size }\end{array}$ & $t$ & df & $P$ & $\mathbf{F}$ & & & $P$ \\
\hline $\begin{array}{l}\text { Continuous Performance Test } \\
\text { hit reaction time }\end{array}$ & -3.73 & 1.40 & -0.26 & 2.64 & 376 & 0.01 & 0.22 & 1.35 & 0.02 & -0.16 & 376 & 0.872 & 4.13 & 1 & 376 & 0.04 \\
\hline $\begin{array}{l}\text { Continuous Performance Test } \\
\text { detectability }\end{array}$ & -0.08 & 0.01 & -0.26 & 1.46 & 376 & 0.15 & 0.07 & 0.05 & 0.14 & -1.19 & 376 & 0.23 & 3.53 & 1 & 376 & 0.06 \\
\hline Digital Symbol Substitution Test ${ }^{\mathrm{a}}$ & 2.00 & 1.06 & 0.14 & -1.88 & 375 & 0.06 & 1.73 & 1.05 & 0.12 & -1.66 & 375 & 0.10 & 0.03 & 1 & 375 & 0.86 \\
\hline Digit Span Forward & 0.42 & 0.24 & 0.14 & -1.74 & 374 & 0.08 & 0.08 & 0.24 & 0.03 & -0.33 & 374 & 0.74 & 1.01 & । & 374 & 0.31 \\
\hline Digit Span Backward & 0.34 & 0.25 & 0.12 & -1.38 & 373 & 0.17 & -0.41 & 0.25 & -0.15 & 1.66 & 373 & 0.10 & 4.66 & 1 & 373 & 0.03 \\
\hline Visual Span & -0.17 & 0.22 & -0.10 & 0.78 & 374 & 0.44 & -0.23 & 0.21 & -0.13 & 1.09 & 374 & 0.28 & 0.04 & I & 374 & 0.84 \\
\hline Stroop Interference T score & 1.26 & 1.54 & 0.11 & -0.82 & 375 & 0.41 & -4.40 & 1.51 & -0.38 & 2.91 & 375 & 0.00 & 6.82 & । & 375 & 0.01 \\
\hline $\begin{array}{l}\text { Wisconsin Card Sorting Test } \\
\text { categories }\end{array}$ & 0.22 & 0.25 & 0.11 & -0.91 & 373 & 0.36 & -0.41 & 0.24 & -0.20 & 1.67 & 373 & 0.10 & 3.31 & I & 373 & 0.07 \\
\hline $\begin{array}{l}\text { Wisconsin Card Sorting Test } \\
\text { non-perseverative error }\end{array}$ & -2.27 & 1.69 & -0.20 & 1.34 & 311 & 0.18 & -2.46 & 1.59 & -0.22 & 1.54 & 311 & 0.12 & 0.01 & 1 & 311 & 0.94 \\
\hline
\end{tabular}

${ }^{a}$ Treatment main effect on digit symbol substitution test: $F=6.15, \mathrm{df}=1,375, p=0.013$.

${ }^{b}$ Treatment main effect on Wisconsin Card Sorting Test non-perseverative error: $F=4.12, d f=|3| 1, p=0.043$.

abstain from smoking until testing was completed. This procedure would have reduced within-person changes in acute nicotine levels during cognitive testing over the course of the study.

Our findings are generally consistent with previous studies, which have reported beneficial effects of varenicline on cognition similar to those observed with nicotine. Smith et al (2009) found significant improvements in an open label study $(N=12)$ in schizophrenia in some areas of cognition, particularly in the areas of verbal learning and memory. Others have also reported cognitive improvements in non-psychiatric populations in attention (Patterson et al, 2009) and working memory (Loughead et al, 2010; Patterson et al, 2009) that are similar to what is observed in animal studies (Rollema et al, 2007). Also a recently published double-blind trial (Hong et al, 2011) found that varenicline significantly reduced P50 sensory gating deficits in non-smokers and reduced startle reactivity and improved executive function regardless of smoking status. That study used a lower dose and had a smaller sample size. Our current study did not attempt to identify the optimal dose of varenicline to maximize the cognitive effects of this medication. In our study, titration up to $2 \mathrm{mg} /$ day varenicline was selected as described in a study by Gonzales et al (2006), which attempted to find the optimal dose in healthy that balanced efficacy and side effects. Some studies suggest that second-generation antipsychotics may improve cognitive deficits relative to first-generation antipsychotics (Keefe et al, 2004), while others have not found any differences between antipsychotic classes (Sergi et al, 2007). In this study, there was no antipsychotic type $\times$ treatment interaction effect on cognitive function. Failure to detect such effects could be due to lack of power to detect differences in treatment effects among the groups.

Few prospective studies have measured the safety and psychiatric effects of varenicline treatment in people with schizophrenia. Some reports find no worsening in psychiatric symptoms in people with schizophrenia (Hong et al, 2011; Smith et al, 2009; Evins and Goff, 2008), while one paper reports aggravation of psychotic symptoms with varenicline (Freedman, 2007). We did not observe any significant change in PANSS or SANS scores after adjunct varenicline treatment. Two subjects treated with varenicline were withdrawn for worsening of psychotic symptoms as were two subjects treated with placebo. Thus, it is not clear if varenicline was the cause of the clinical worsening.

Concerns regarding depression and suicidal ideation following varenicline treatment have been raised (US FDA, 2008). In our study, no subjects showed significant depressive symptoms or suicidal ideations. Our study excluded major depressive disorder so we could not assess worsening of pre-existing depression. Previous smoking cessation studies have reported depressive symptoms during cessation from cigarette smoking (Breslau et al, 2005). Therefore, varenicline should be used with caution in schizophrenia patients with current or past depressive disorders.

Nausea, insomnia, headache, and abnormal dreams are common adverse events associated with varenicline use (Gonzales et al, 2006). In this study, nausea and headache were significantly higher in varenicline group than in placebo group. No clinically significant drug interactions with varenicline have been discovered to date. In this study, we did not measure pharmacokinetic parameters, however, no significant change in extrapyramidal symptoms or akathisia was noted with varenicline treatment.

Several limitations to our study should be considered. First, we focused on attention in this study and selected neuropsychological tests relatively sensitive to measuring attention. Measuring a broad range of cognitive domains such as with MATRICS Consensus Cognitive Battery (MCCB; Marder and Fenton, 2004) may better evaluate cognitive effects in people with schizophrenia; however, a Korean version of the MCCB was not available when this trial was conducted. Second, $75.2 \%$ of subjects were taking anticholinergic medications and $44 \%$ taking benzodiazepines, which may affect cognition. However, the dose of anticholinergic medications remained fixed throughout the 
study to try to minimize their effect on treatment-related changes in cognition. Also, the baseline levels of neuropsychological impairment in these chronic patients may have been too severe to allow improvement during therapy; different results might be seen in patients in early stages of the illness or during acute exacerbations. Also, in our analyses multiple treatment-placebo comparisons were performed which increases the chance of a type I error. Nominally significant findings $(p<0.05)$ were only seem in secondary analyses with mixed models using all available data at all visits on all subjects treated; the pre-designated primary analysis of change scores from baseline to week 8 on completers found no significant varenicline-placebo differences. The primary analysis may have lacked power compared with the secondary analyses, because those analyses incorporated more data from repeated observations and included subjects who dropped out early, and also included exploratory tests for treatment $\times$ smoking interactions. Finally, blood levels of nicotine or varenicline were not measured to evaluate these levels on cognitive performance and significant practice effects were seen in this study.

In summary, our findings suggest some cognitive improvements with use of adjunctive varenicline treatment with antipsychotics in people with schizophrenia, although this was not true across all cognitive measures considered. In certain cases, cognitive improvement with varenicline depended on status as smokers or non-smokers. Further studies are needed to confirm our findings, and to evaluate whether improvements in these cognitive measures are reflected in functional improvements in daily life.

\section{ACKNOWLEDGEMENTS}

This study was supported by a grant from the Stanley Medical Research Institute (07TGS-1051). No authors received any financial support from the pharmaceutical industry for this study. Trial Registration: Clinicaltrials.gov Identifier NCT00523445.

\section{DISCLOSURE}

The authors declare no conflict of interest.

\section{REFERENCES}

Addy N, Levin ED (2002). Nicotine interactions with haloperidol, clozapine and risperidone and working memory function in rats. Neuropsychopharmacology 27: 534-541.

Andreasen NC (1982). Negative symptoms in schizophrenia. Definition and reliability. Arch Gen Psychiatry 39: 784-788.

Arthur D, Levin ED (2002). Chronic inhibition of alpha4beta2 nicotinic receptors in the ventral hippocampus of rats: impacts on memory and nicotine response. Psychopharmacology (Berl) 160: $140-145$.

Barnes TR (2003). The Barnes Akathisia Rating Scale-revisited. J Psychopharmacol 17: 365-370.

Barr RS, Culhane MA, Jubelt LE, Mufti RS, Dyer MA, Weiss AP et al (2008). The effects of transdermal nicotine on cognition in nonsmokers with schizophrenia and nonpsychiatric controls. Neuropsychopharmacology 33: 480-490.
Bencherif M, Schmitt JD (2002). Targeting neuronal nicotinic receptors: a path to new therapies. Curr Drug Targets CNS Neurol Disord 1: 349-357.

Breese CR, Lee MJ, Adams CE, Sullivan B, Logel J, Gillen KM et al (2000). Abnormal regulation of high affinity nicotinic receptors in subjects with schizophrenia. Neuropsychopharmacology 23: 351-364.

Breslau N, Schultz LR, Johnson EO, Peterson EL, Davis GC (2005). Smoking and the risk of suicidal behavior: a prospective study of a community sample. Arch Gen Psychiatry 62: 328-334.

Coe PR, Brooks MG, Vetelino MC, Wirtz EP, Arnold J, Huang SB et al (2005). Varenicline: an alpha4beta2 nicotinic receptor partial agonist for smoking cessation. J Med Chem 48: 3474-3477.

Conners CK (2004). The Continuous Performance Test (CPTII). Multi-Health Systems Inc.: North Tonawanda, New York.

Evins AE, Goff DC (2008). Varenicline treatment for smokers with schizophrenia: a case series. J Clin Psychiatry 69: 1016.

Freedman R (2007). Exacerbation of schizophrenia by varenicline. Am J Psychiatry 164: 1269.

George TP, Vessicchio JC, Termine A, Sahady DM, Head CA, Pepper WT et al (2002). Effects of smoking abstinence on visuospatial working memory function in schizophrenia. $\mathrm{Neu}$ ropsychopharmacology 26: 75-85.

Golden CJ, White L, Combs T, Morgan M, McLane D (1999). WMS$\mathrm{R}$ and MAS correlations in a neuropsychological population. Arch Clin Neuropsychol 14: 265-271.

Gonzales D, Rennard SI, Nides M, Oncken C, Azoulay S, Billing CB et al (2006). Varenicline, an alpha4beta2 nicotinic acetylcholine receptor partial agonist, vs sustained-release bupropion and placebo for smoking cessation: a randomized controlled trial. JAMA 296: 47-55.

Green MF (2006). Cognitive impairment and functional outcome in schizophrenia and bipolar disorder. J Clin Psychiatry 67 (Suppl 9): 3-8.

Guy W, Bonato RR (1970). In: Chevy Chase Md (eds). Manual for the ECDEU Assessment Battery, revised 2nd edn. National Institute of Mental Health, George Washington University. pp 12.1-12.6.

Hamilton M (1960). A rating scale for depression. J Neurol Neurosurg Psychiatry 23: 56-62.

Heaton RK, Chelune GJ, Talley JL (1993). Wisconsin Card Sorting Test, Manual. Psychological Assessment Resources: Odessa, Florida.

Hong LE, Thaker GK, McMahon RP, Summerfelt A, Rachbeisel J, Fuller FL et al (2011). Effects of moderate-dose treatment with varenicline on neurobiological and cognitive biomarkers in smokers and nonsmokers with schizophrenia or schizoaffective disorder. Arch Gen Psychiatry (e-pub ahead of print 1 August 2011).

Jubelt LE, Barr RS, Goff DC, Logvinenko T, Weiss AP, Evins AE (2008). Effects of transdermal nicotine on episodic memory in non-smokers with and without schizophrenia. Psychopharmacology 199: 89-98.

Kantrowitz JT, Revheim N, Pasternak R, Silipo G, Javitt DC (2009). It's all in the cards: effect of stimulus manipulation on Wisconsin Card Sorting Test performance in schizophrenia. Psychiatry Res 168: 198-204.

Kay SR, Fiszbein A, Opler LA (1987). The positive and negative syndrome scale (PANSS) for schizophrenia. Schizophr Bull 13: 261-276.

Keefe RS, Seidman LJ, Christensen BK, Hamer RM, Sharma T, Sitskoorn MM et al (2004). Comparative effect of atypical and conventional antipsychotic drugs on neurocognition in first-episode psychosis: a randomized, double-blind trial of olanzapine versus low doses of haloperidol. Am J Psychiatry 161: 985-995.

Kelly DL, Buchanan RW, Boggs DL, McMahon RP, Dickinson D, Nelson $\mathrm{M}$ et al (2009). A randomized double-blind trial of atomoxetine for cognitive impairments in 32 people with schizophrenia. J Clin Psychiatry 70: 518-525. 
Leucht S, Kane JM, Kissling W, Hamann J, Etschel E, Engel RR (2005). What does the PANSS mean? Schizophr Res 79: 231-238.

Levin ED, Bradley A, Addy N, Sigurani N (2002). Hippocampal alpha 7 and alpha 4 beta 2 nicotinic receptors and working memory. Neuroscience 109: 757-765.

Levin ED, Wilson W, Rose JE, McEvoy J (1996). Nicotinehaloperidol interactions and cognitive performance in schizophrenics. Neuropsychopharmacology 15: 429-436.

Lezak MD (1995). Neuropsychological Assessment, 3rd edn. Oxford University Press: New York.

Loughead J, Ray R, Wileyto EP, Ruparel K, Sanborn P, Siegel S et al (2010). Effects of the alpha4beta2 partial agonist varenicline on brain activity and working memory in abstinent smokers. Biol Psychiatry 67: 715-721.

Marder SR, Fenton W (2004). Measurement and treatment research to improve cognition in schizophrenia: NIMH MATRICS initiative to support the development of agents for improving cognition in schizophrenia. Schizophr Res 72: 5-9.

Marutle A, Zhang X, Court J, Piggott M, Johnson M, Perry R et al (2001). Laminar distribution of nicotinic receptor subtypes in cortical regions in schizophrenia. J Chem Neuroanat 22: $115-126$.

Maskos U, Molles BE, Pons S, Besson M, Guiard BP, Guilloux JP et al (2005). Nicotine reinforcement and cognition restored by targeted expression of nicotinic receptors. Nature 436: 103-107.

Mihalak KB, Carroll FI, Luetje CW (2006). Varenicline is a partial agonist at alpha4beta2 and a full agonist at alpha7 neuronal nicotinic receptors. Mol Pharmacol 70: 801-805.

Patterson F, Jepson C, Strasser AA, Loughead J, Perkins KA, Gur $\mathrm{RC}$ et al (2009). Varenicline improves mood and cognition during smoking abstinence. Biol Psychiatry 65: 144-149.

Poorthuis RB, Goriounova NA, Couey JJ, Mansvelder HD (2009). Nicotinic actions on neuronal networks for cognition: general principles and long-term consequences. Biochem Pharmacol 78 668-676.

Rabin RA, Sacco KA, George TP (2009). Correlation of prepulse inhibition and Wisconsin Card Sorting Test in schizophrenia and controls: effects of smoking status. Schizophr Res 114: 91-97.

Rollema H, Chambers LK, Coe JW, Glowa J, Hurst RS, Lebel LA et al (2007). Pharmacological profile of the alpha4beta2 nicotinic acetylcholine receptor partial agonist varenicline, an effective smoking cessation aid. Neuropharmacology 52: 985-994.

Sacco KA, Termine A, Seyal A, Dudas MM, Vessicchio JC, Krishnan-Sarin S et al (2005). Effects of cigarette smoking on spatial working memory and attentional deficits in schizophrenia: involvement of nicotinic receptor mechanisms. Arch Gen Psychiatry 62: 649-659.

Sergi MJ, Green MF, Widmark C, Reist C, Erhart S, Braff DL et al (2007). Social cognition [corrected] and neurocognition: effects of risperidone, olanzapine, and haloperidol. Am J Psychiatry 164: 1585-1592.

Simpson GM, Angus JW (1970). A rating scale for extrapyramidal side effects. Acta Psychiatr Scand Suppl 212: 11-19.

Smith RC, Lindenmayer JP, Davis JM, Cornwell J, Noth K, Gupta S et al (2009). Cognitive and antismoking effects of varenicline in patients with schizophrenia or schizoaffective disorder. Schizophr Res 110: 149-155.

US Food and Drug Administration (2008). FDA issues Public Health Advisory on Chantix. FDA News. Available at http://www.fda.gov/bbs/topics/NEWS/2008/NEW01788.html. Accessibility verified February 01, 2008.

Wechsler D (1981). Manual for the Wechsler Adult Intelligence Scale-Revised. The Psychological Corporation: San Antonio.

Woods SW (2003). Chlorpromazine equivalent doses for the newer atypical antipsychotics. J Clin Psychiatry 64: 663-667.

Supplementary Information accompanies the paper on the Neuropsychopharmacology website (http://www.nature.com/npp) 